\title{
A Coxiella burnetii phospholipase A homolog $p l d A$ is required for optimal growth in macrophages and developmental form lipid remodeling
}

\author{
Christopher M. Stead ${ }^{1,2}$, Diane C. Cockrell ${ }^{1}$, Paul A. Beare ${ }^{1}$, Heather E. Miller ${ }^{1}$ and Robert A. Heinzen ${ }^{1 *}$
}

\begin{abstract}
Background: Many gram-negative bacteria produce an outer membrane phospholipase A (PIdA) that plays an important role in outer membrane function and is associated with virulence.

Results: In the current study, we characterized a pldA mutant of Coxiella burnetii, an intracellular gram-negative pathogen and the agent of human $\mathrm{Q}$ fever. The $C$. burnetti pldA open reading frame directs synthesis of a protein with conserved PldA active site residues. A C. burnetii $\Delta p / d A$ deletion mutant had a significant growth defect in THP-1 macrophages, but not axenic medium, that was rescued by complementation. Thin layer chromatography was employed to assess whether pldA plays a role in remodeling membrane lipids during C. burnetii morphological differentiation. Extracted lipids were analyzed from replicating, logarithmic phase large cell variants (LCVs), non-replicating, stationary phase small cell variants (SCVs), and a mixture of LCVs and SCVs. Similar to Escherichia coli, all three forms contained cardiolipin (CL), phosphatidylglycerol (PG) and phosphatidylethanolamine (PE). However, PE and PG were present in lower quantities in the SCV while three additional lipid species were present in higher quantities. Co-migration with standards tentatively identified two of the three SCV-enriched lipids as lyso-phosphatidylethanolamine, a breakdown product of PE, and free fatty acids, which are generally toxic to bacteria. Developmental form lipid modifications required the activity of PldA.
\end{abstract}

Conclusions: Collectively, these results indicate developmentally-regulated lipid synthesis by C. burnetii contributes to colonization of macrophages and may contribute to the environmental stability and the distinct biological properties of the SCV.

Keywords: Coxiella, Lipid, Fatty acids, Phospholipase A, Small cell variant

\section{Background}

Coxiella burnetii is a gram-negative intracellular pathogen noted for high environmental stability and a low infectious dose via the aerosol route of infection [1]. C. burnetii causes an acute flu-like illness known as Q fever. Following infection, the organism traffics to a vacuole with lysosomal characteristics [2]. Replication of the organism proceeds via a bi-phasic developmental cycle, during which it transitions from a large cell variant (LCV) to a

\footnotetext{
* Correspondence: rheinzen@niaid.nih.gov

${ }^{1}$ Coxiella Pathogenesis Section, Laboratory of Bacteriology, Rocky Mountain Laboratories, National Institute of Allergy and Infectious Diseases, National Institutes of Health, Hamilton, Montana, USA

Full list of author information is available at the end of the article
}

small cell variant (SCV) developmental form [3-5]. The LCV is considered the replicative form and is present during logarithmic growth. As bacterial growth enters stationary phase, LCVs differentiate into SCVs. As compared to LCVs, SCVs have low metabolic activity and increased resistance to osmotic and physical stressors [5]. These resistance properties are thought to promote environmental stability by the SCV [4].

Despite the apparent importance of SCVs in C. burnetii disease transmission and pathogenesis, relatively little is known about biochemical changes during transition that confer the unique biological properties of the SCV. Ultrastructural differences between LCVs and SCVs

(c) The Author(s). 2018 Open Access This article is distributed under the terms of the Creative Commons Attribution 4.0 International License (http://creativecommons.org/licenses/by/4.0/), which permits unrestricted use, distribution, and reproduction in any medium, provided you give appropriate credit to the original author(s) and the source, provide a link to the Creative Commons license, and indicate if changes were made. The Creative Commons Public Domain Dedication waiver (http://creativecommons.org/publicdomain/zero/1.0/) applies to the data made available in this article, unless otherwise stated. 
predicted to promote SCV stability include a thicker cell envelope, different peptidoglycan cross linking, condensed chromatin, and synthesis of two highly basic DNA binding proteins [4-6].

The gram-negative cell envelope is composed of an inner and outer membrane, with peptidoglycan separating the two membranes. Both leaflets of the inner membrane are composed of phospholipids, whereas, the outer membrane has an inner leaflet of phospholipids and an outer leaflet of lipopolysaccharide. Phospholipid modifications are common in bacteria and can provide an increase in resistance properties [7]. For example, cyclopropanation of phospholipid acyl chains in Escherichia coli increases resistance to acid stress [8].

Considering the importance of phospholipids in cell envelope function, few studies of these molecules have been conducted in C. burnetii. A report published in 2002 demonstrated phosphatidylethanolamine (PE), phosphatidylserine (PS), phosphatidylcholine (PC), and phosphatidylglycerol (PG) in both virulent phase I and avirulent phase II $C$. burnetii, which produce full-length and truncated lipopolysaccharide, respectively [9]. Phosphatidylinositol (PI) was also detected in phase II bacteria [9]. A subsequent study showed no PI in C. burnetii, which is consistent with the absence of genes responsible for synthesis of this lipid $[10,11]$. Moreover, PI is common in eukaryotes but rare in eubacteria [12]. Both studies used C. burnetii purified from infected hen's eggs; thus, it is possible that contaminating eukaryotic host cell membrane was in bacterial preparations. The majority of $C$. burnetii fatty acids are branched, with little difference in the profiles between the cell envelope of LCVs and SCVs $[13,14]$.

In the current study, we utilized axenic culture to characterize the lipid profile of C. burnetii as it transitions from the LCV to SCV developmental form. We show marked changes in lipid content during differentiation that are attributable to the activity of a predicted outer membrane phospholipase A (PldA).

\section{Results}

\section{C. burnetii pldA is required for optimal growth in macrophages}

CBU0489 is annotated as an outer membrane phospholipase A (pldA)-encoding gene [11]. C. burnetii PldA displayed $40 \%$ amino acid identity (E-value of $1 \times 10^{-44}$ ) with the E. coli homolog (accession no. BAE77480.1). Amino acid residues comprising the PldA consensus motif and active site residues were highly conserved [15] (Fig. 1a).

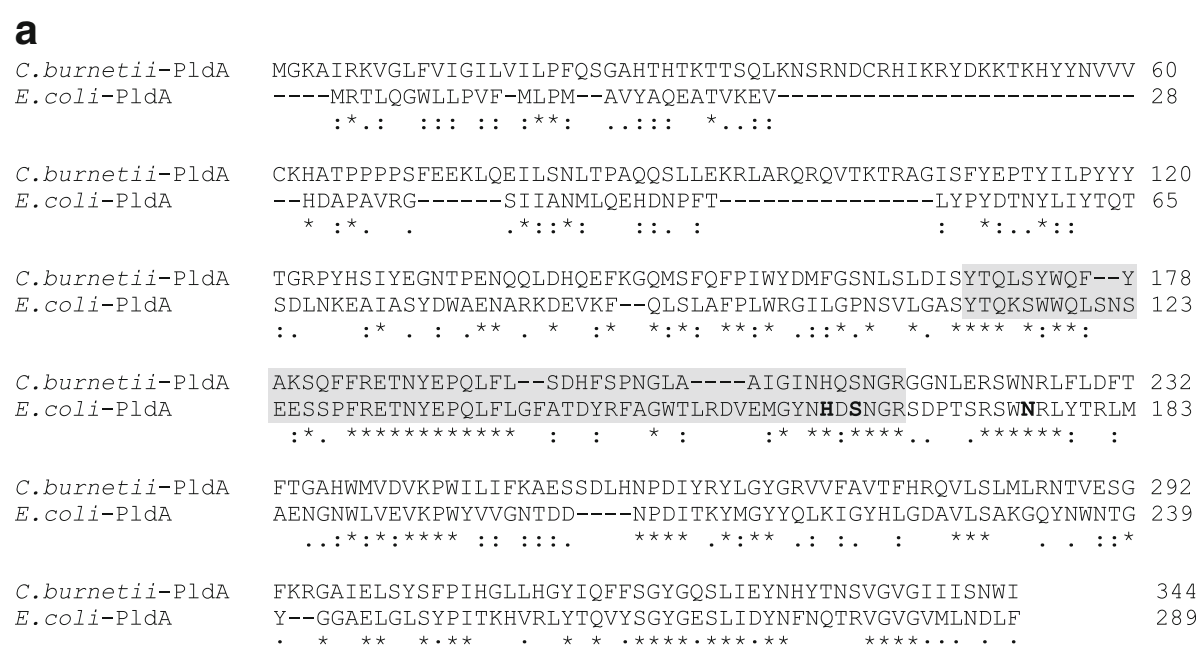

b

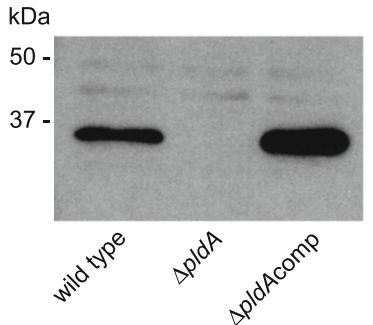

Fig. 1 Generation of a C. burnetii pldA mutant. a Alignment of PldA from E. coli and C. burnetii. The grey region shows the consensus sequence motif YTQ- $X_{n}-G-X_{2}-H-X-S N G$ for PIdA enzymes. Bold amino acids show known active site residues [15]. b Lysates from C. burnetii wild type, $\Delta p / d A$, and $\triangle$ pldAcomp strains after 6 days of growth in ACCM-2 (early SCV) were probed by immunoblotting with an anti-PldA polyclonal antibody 
To investigate the role of pldA in C. burnetii lipid metabolism, a null mutant was generated using allelic exchange (Additional file 1: Figure S1). The mutant was subsequently complemented using a Tn7 construct to insert a single copy of pldA into the chromosome under the control of a native promoter [16]. An immunoblot of cell lysates prepared from wild type, $\Delta p l d A$, and $\Delta p l d A$ comp $C$. burnetii strains demonstrated loss of PldA in the mutant, which was restored upon complementation (Fig. 1b).

To determine the importance of pldA during host cell infection, growth of the $\triangle p l d A$ and $\triangle p l d A$ comp strains were assessed in synthetic media and THP-1 macrophages. When axenically cultivated, mutant and wild type bacteria replicated to similar levels (Fig. 2a). However, during infection of macrophages, mutant bacteria displayed a significant growth defect that was partially restored upon complementation (Fig. 2a). The mutant phenotype correlated with significantly smaller Coxiella-containing vacuoles $(\mathrm{CCV})$ with fewer organisms (Fig. 2b and c).

\section{C. burnetii produces a unique lipid profile that changes during the LCV to SCV transition}

To gain insight into pldA-driven lipid modifications associated with the development cycle of $C$. burnetii, we first examined the phospholipid content of wild type bacteria. To avoid contamination of host cell-derived lipids, C. burnetii lipid analysis was conducted using bacteria cultured in ACCM-2 (acidified citrate cysteine medium-2), which is an appropriate model for studying C. burnetii developmental transitions [6]. Four, 7, and 14 day time points were taken to represent $\mathrm{LCV}, \mathrm{LCV}+\mathrm{SCV}$, and SCV developmental forms, respectively. Lipids were isolated as described in the Materials and Methods and analyzed by thin layer chromatography (TLC) along with $E$. coli lipids. E. coli is considered a model organism for gram-negative phospholipid biosynthesis $[17,18]$. TLC showed that the C. burnetii lipid profile is dynamic during LCV to SCV transition and different from the lipid profile of $E$. coli (Fig. 3). Both E. coli and C. burnetii synthesized three major lipid species based on retardation factor $\left(R_{f}\right)$ : CL $\left(R_{f}=0.77\right)$, PG $\left(R_{f}=0.59\right)$, and PE $\left(R_{f}=0.43\right)$ (Fig. 3) [19]. However, C. burnetii produced three additional lipid species that were substantially increased in SCVs. In contrast, PG and PE were reduced in SCVs.

\section{C. burnetii likely produces lyso-phosphatidylethanolamine and free fatty acids}

PldA catalyzes the removal of an acyl chain from a phospholipid to produce a lyso-phospholipid (lyso-PL) and a free fatty acid (FFA) (Fig. 4a) [20, 21]. Therefore, it is logical to assume that some of the lipids enriched in the SCV could be Lyso-PLs or FFAs. To investigate this assumption, an 18-1 lyso-phosphatidylethanolamine (18-1 Lyso-PE) and palmitoleic acid standard were analyzed alongside $C$. burnetii lipids. By TLC, an 18-1 Lyso-PE standard $\left(R_{f}=0.14\right)$ had a similar $R_{f}$ to lipid $1\left(R_{f}=0.16\right)$, putatively identifying this species as Lyso-PE (Fig. 4b). Lipid $3\left(R_{\mathrm{f}}=0.96\right)$ had a similar $R_{\mathrm{f}}$ to the palmitoleic acid standard $\left(R_{f}=0.96\right)$, putatively identifying this species as FFA.

\section{C. burnetii pldA participates in lipid remodeling associated with LCV to SCV transition}

The phospholipid profile of $\Delta p l d A$ and $\Delta p l d A$ comp strains at 4 and 14 days were compared to wild type bacteria (Fig. 5). The three phospholipid profiles at day 4 appeared the same, However, at day 14, the decrease in $\mathrm{PE}$ and PG was no longer evident in the $\Delta p l d A$ mutant nor was the increase in lipids 1,2 , and 3 . The wild type profile was restored in the $\Delta p l d A$ comp strain. These data indicate $p l d A$ is responsible for membrane remodeling of the SCV developmental form.

\section{Discussion}

Compositional differences between LCV and SCV developmental forms that contribute to their distinct biological and structural properties are poorly defined. A few proteins have been identified that are differentially synthesized by the LCV and SCV, including the small basic DNA binding proteins ScrA and $\mathrm{Hq} 1$ that are associated with the condensed chromatin of SCVs [22-24]. Warrier et al. [25] defined 15 developmentally regulated small RNAs that may play roles in differentiation. Sandoz and coworkers [26] recently demonstrated major changes in peptidoglycan structure during LCV to SCV transition. Here, we demonstrate additional changes to the SCV cell envelope that involve PldA-dependent changes in lipid composition.

PldA-dependent breakdown of PE produces FFA and Lyso-PE. The accumulation of FFA by the C. burnetii SCV is perplexing as these molecules are considered toxic to bacteria [27]. In fact, we are aware of only one organism that stores large amounts of medium-to-long chain saturated fatty acids, an anaerobic bacterium known as G12 that is related to Eubacterium cylidroides [28]. This bacterium appears to accumulate FFA during homeoviscous adaptation to environmental stress. Many bacterial species utilize stores of lipophilic compounds as energy and carbon sources, generally in the form of polyhydroxyalkanoates, such as poly(3-hydroxybutyrate) [29]. How C. burnetii tolerates FFA toxicity and the potential role(s) these compounds play in pathogen physiology are intriguing questions. Given that the greatest amount of FFA is seen in the SCV, these lipid molecules may serve as a nutrient source for outgrowth of the LCV during the initial stages of infection, when the $\mathrm{CCV}$ may be limited in nutrients $[2,30]$. 

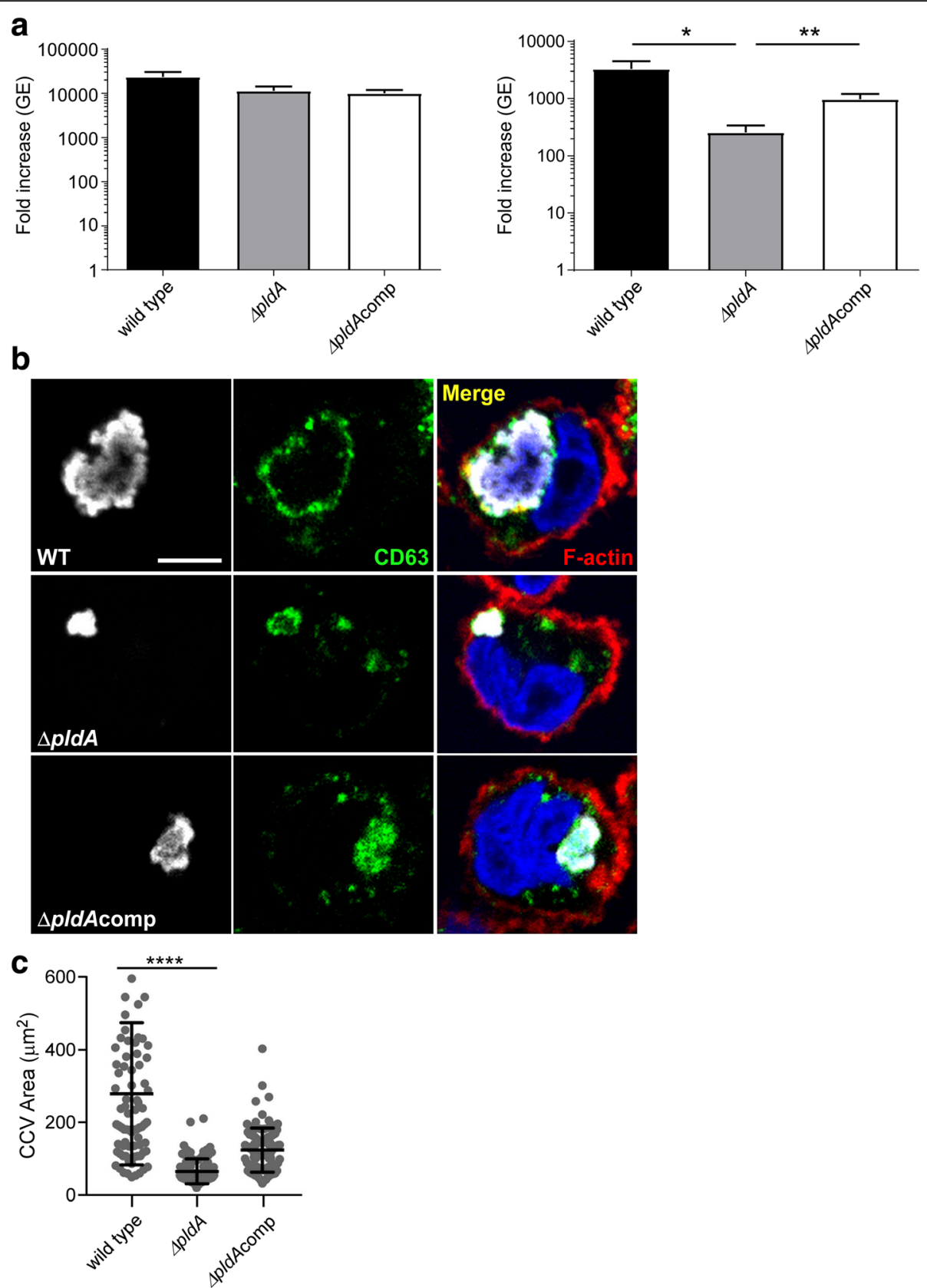

Fig. 2 A $\Delta p / d A$ mutant has impaired growth in THP-1 macrophages. a Growth of C. burnetii wild type, $\Delta p / d A$, and $\triangle p l d A C o m p$ strains in ACCM-2 (left panel) and THP-1 macrophages (right panel). Data represent fold increases in genome equivalents (GE) after 6 days of growth (early SCV) for 3 independent experiments performed in triplicate. Asterisks indicate a statistically significant difference $\left({ }^{*}=P<0.05,{ }^{* *}=P<0.01\right)$ as determined by the unpaired Student $t$ test. $\mathbf{b}$ Immunofluorecence micrographs of $C$. burnetii wild type, $\Delta p / d A$, and $\Delta p / d A c o m p$ strains after 3 days of growth (LCV). Bacteria are colored white, the vacuole membrane green, the THP-1 cell border red, and the nucleus blue. c Size of Coxiella-containing vacuoles (CCV) at 3 days post-infection, Vacuole size was measured with Fiji and the data are representative of three independent experiments. Asterisks indicate a statistically significant difference. $\left(^{* * *}=P<0.0001\right)$. Scale bar, $5 \mu \mathrm{m}$

Lysophopholipids affect membrane stiffness and fluidity, which in turn influences membrane permeability and pore function [20,31]. PldA-dependent accumulation of lysophopholipids in the Helicobacter pylori membrane promotes release of urease and VacA toxin [32, 33]. Both molecules enhance adherence to epithelial cells and development of ulcer disease [32, 33]. In E. coli, PldA facilitates release of bacteriocins $[34,35]$. Shigella flexneri needs PldA for efficient type III secretion and to maintain membrane integrity [36]. We show that PldA-deficient C. burnetii clearly has a growth defect in human macrophages, although the precise mechanism of this attenuation 


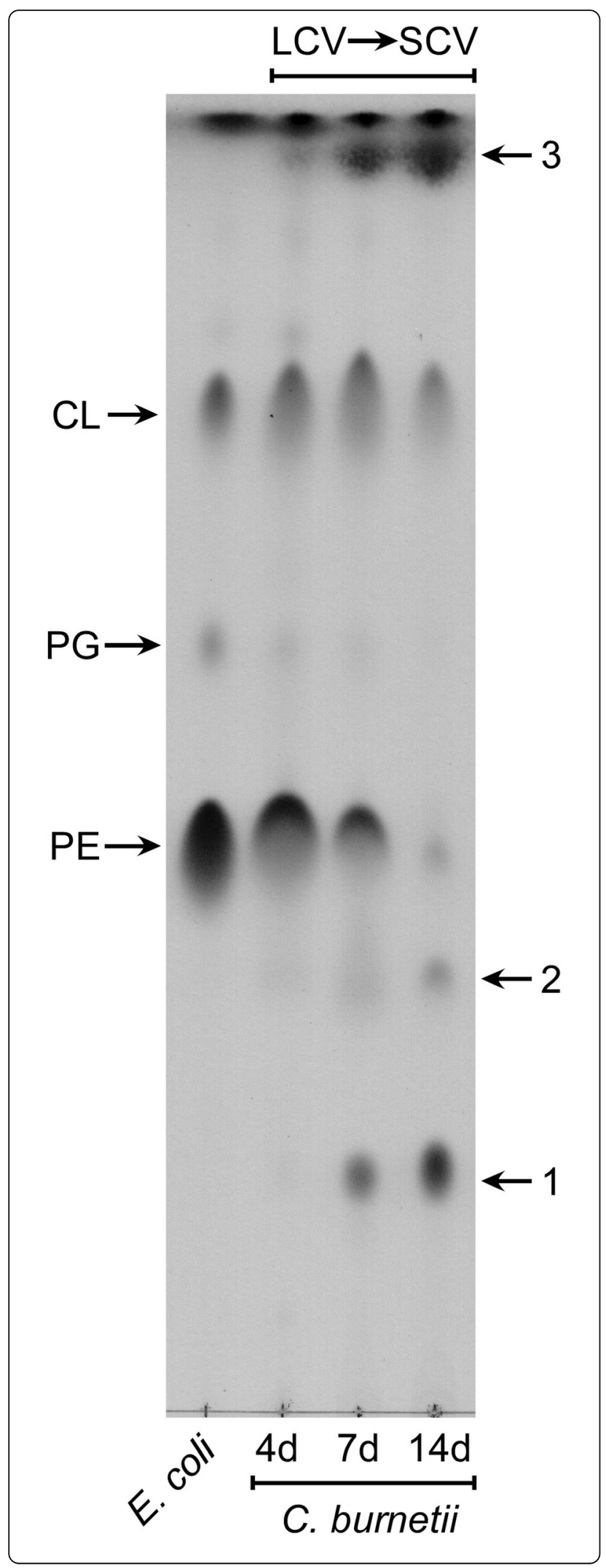

Fig. 3 The C. burnetii lipid profile changes during LCV to SCV transition. Lipids were isolated from 4,7 , and 14 day C. burnetii axenic cultures to represent different stages of the developmental cycle. Lipids were analyzed by TLC and spotted according to mass: C. burnetii $=550 \mu \mathrm{g}$, E. coli $=200 \mu \mathrm{g}$. Lipid species 1, 2, and 3 were enriched in the SCV while phosphatidylethanolamine and phosphatidylglycerol were diminished. Abbreviations: $\mathrm{CL}$, cardiolipin; PG, phosphatidylglycerol; PE, phosphatidylethanolamine

remains to be defined. One possibility is that PldA contributes to a recently described Sec-mediated secretion system of C. burnetii [37]. Another possibility is that mutant SCVs are less resistant to the lysosomal environment.

\section{Conclusion}

In this work, developmentally-regulated synthesis of $C$. burnetii lipids was described. PldA was responsible for enrichment of Lyso-PE and FFA in the SCV. These data, along with major modifications of SCV peptidoglycan [26], indicate the $C$. burnetii cell envelope undergoes substantial remodeling during morphologic differentiation. PldA also promotes pathogen growth in the harsh, lysosome-like environment of macrophages. Further characterization of PldA and the unusual lipids generated by the enzyme will provide needed insight into $C$. burnetii resistance and pathogenesis.

\section{Methods}

\section{Bacterial and mammalian cell culture}

Bacterial strains are described in Additional file 2: Table S1. ACCM-2 or ACCM-2 agarose was employed to grow $C$. burnetii as previously described [38]. E. coli strains were grown in Luria-Bertani (LB) broth at $37^{\circ} \mathrm{C}$. E. coli W3110 cells were used for lipid isolation while $E$. coli Stellar cells were used for recombinant DNA procedures. LB agar plates containing $50 \mu \mathrm{g}$ of kanamycin/ml or $10 \mu \mathrm{g}$ of chloramphenicol $/ \mathrm{ml}$ were used to select $E$. coli transformants. The human acute monocytic leukemia cell line THP-1 (TIB-202; American Type Culture Collection) was grown at $37{ }^{\circ} \mathrm{C}$ and $5 \% \mathrm{CO}_{2}$ in RPMI 1640 medium (Invitrogen) supplemented with $10 \%$ fetal bovine serum (Hyclone).

\section{Recombinant DNA techniques}

Plasmids used in the study are listed in Additional file 2: Table S1. Accuprime Pfx DNA polymerase (Invitrogen) and oligonucleotide primers (Integrated DNA Technologies) were employed in PCR. Primer sequences are listed in Additional file 3: Table S2. PCR products were cloned using the In-Fusion PCR cloning system (BD Clontech). Restriction enzymes were purchased from New England Biolabs.

\section{Construction of $\mathrm{pJC}$-amp and pMini-Tn7T-Kan}

For construction of pJC-Amp, the 1169 promoter and amp gene were amplified from pJB-CAT by PCR. The PCR 


\section{a}

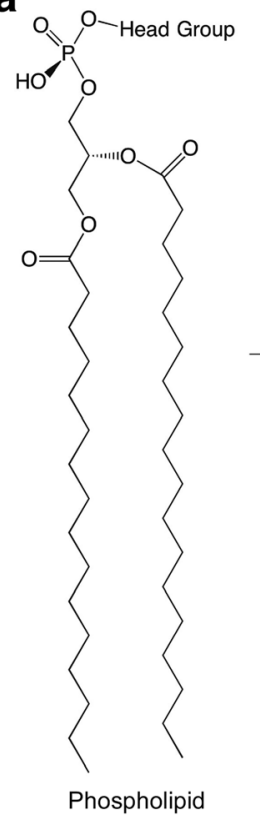

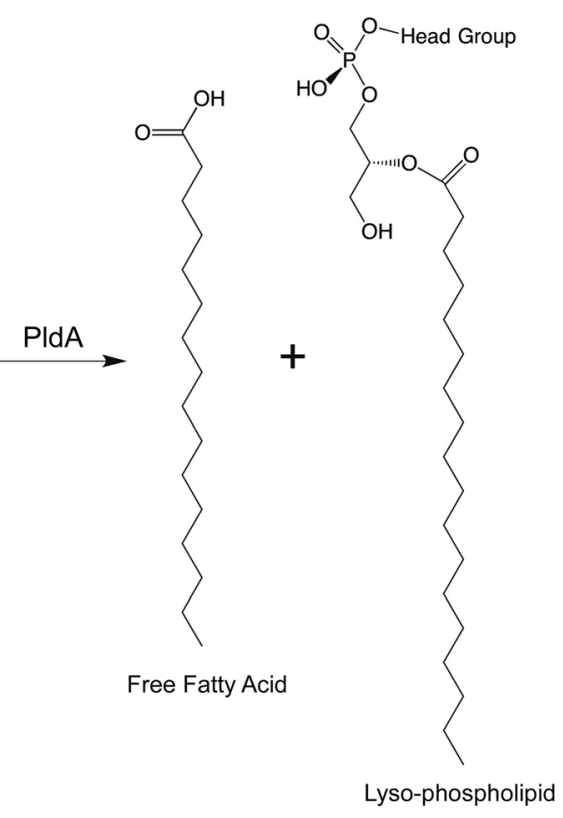

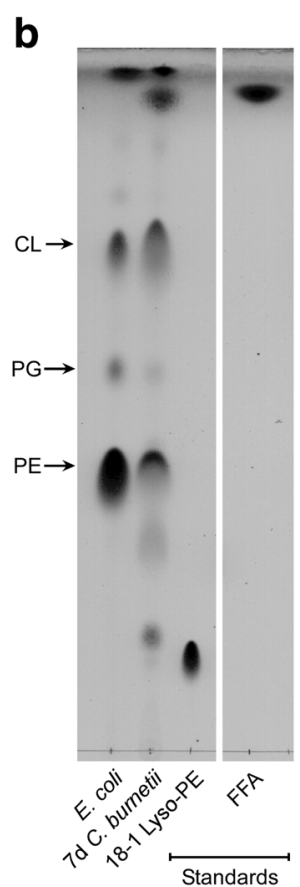

Fig. 4 Identification of C. burnetii SCV enriched lipids. PIdA hydrolyzes a variety of phospholipids that contain a polar head group and acyl-chains containing 14 or more carbons at the $s n-1$ or $s n-2$ position $[20,21]$. a Hydrolysis of a phospholipid acyl chain at the sn-1 position to produce a lyso-phospholipid and a free fatty acid. $\mathbf{b} R_{\mathrm{f}}$ values were compared to purchased standards. All samples were run on the same TLC plate with the image split to exclude irrelevant samples. Abbreviations: PE; phosphatidylethanolamine; PG, phosphatidylglycerol; $C$, cardiolipin; FFA, free fatty acids; 18-1 Lyso-PE, 18-1 lyso-phosphatidylethanolamine

products were cloned by In-Fusion into SalI/NheI-digested pJC-CAT to create pJC-Amp. For construction of pMiniTn7T-Kan, the $1169^{P}-k a n$ fragment was amplified from pJB-Kan by PCR. The $1169^{P}-$ kan amplicon was cloned by In-Fusion into Sall-digested pMini-Tn7T-CAT to create pMini-Tn7T-Kan.

\section{Construction of pJC-amp::pldA-5'3'-CAT for targeted gene deletion}

The pldA 5' and 3' flanking regions were amplified from Nine Mile (RSA439) genomic DNA by PCR. The PCR products were cloned by In-Fusion into BamHI/SalIdigested pJC-Amp to create pJC-Amp::pldA-5' $3^{\prime}$. The $1169^{P}$-cat fragment was amplified from pJB-CAT by PCR. The $1169^{P}$-cat amplicon was cloned by In-Fusion into PstI-digested pJC-Amp::pldA-5' 3 ' to create the knock out vector pJC-Amp::pldA-5'3'-CAT.

\section{Construction of pMini-Tn7T-Kan::pldAcomp for complementation}

The pldA gene and its upstream promoter region was amplified from Nine Mile (RSA439) genomic DNA by PCR. The PCR product was cloned by In-Fusion into EcoRI-digested pMini-Tn7T-Kan to create pMini-Tn7TKan::pldA comp.

\section{C. burnetii gene deletion and complementation}

Deletion of pldA was achieved as previously described using pJC-Amp::pldA-5' $3^{\prime}$-CAT and $3 \mu \mathrm{g} / \mathrm{ml}$ chloramphenicol for antibiotic selection [39]. The mutant strain was cloned by picking colonies propagated on ACCM-2 agarose. Gene deletion was confirmed by PCR. C. burnetii $\triangle p l d A$ was complemented with single copy pMini-Tn7TKan::pldAcomp as previously described using $350 \mu \mathrm{g} / \mathrm{ml}$ kanamycin for antibiotic selection [16].

\section{Antibody generation and immunoblotting of $C$. burnetii lysates}

Monospecific rabbit polyclonal antibody directed against C. burnetii PldA was generated using the PldA-specific synthetic peptide CRHIKRYDKKTKHY (Alpha Diagnostic International, San Antonio, TX). Cell lysates were prepared by boiling $2 \times 10^{8}$ genomic equivalents (GE) of each C. burnetii strain in Laemmli sample buffer for $10 \mathrm{~min}$. Proteins were separated by sodium dodecyl sulfatepolyacrylamide gel electrophoresis using a $4-20 \%$ gel (Bio-Rad), transferred to nitrocellulose, and probed with the anti-PldA antibody. Reacting proteins were detected using anti-rabbit IgG secondary antibodies conjugated to horseradish peroxidase (Thermo Scientific, Waltham, MA) and chemiluminescence using ECL Pico reagent (Thermo Scientific). 


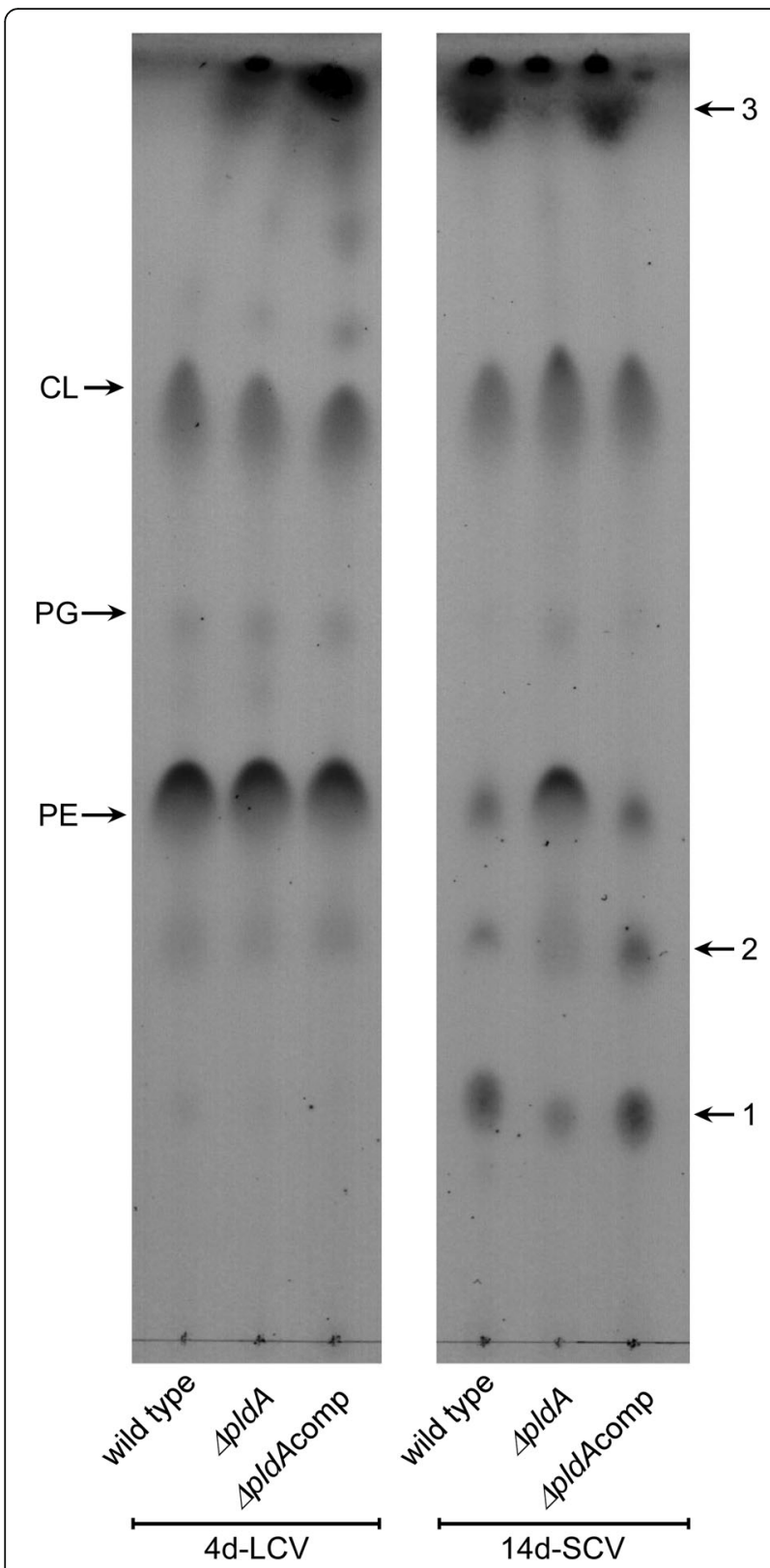

Fig. 5 PldA is required for C. burnetii lipid changes during developmental transition. LCVs and SCVs were generated by growing C. burnetii wild type, $\Delta p / d A$,and $\Delta p l d A c o m p$ strains in ACCM-2 for 4 and 14 days, respectively. Lipids were isolated and $400 \mu \mathrm{g}$ of each sample was analyzed by TLC. Abbreviations: PE, phosphatidylethanolamine; $\mathrm{PG}$, phosphatidylglycerol; $\mathrm{CL}$, cardiolipin

\section{Quantification of $C$. burnetii replication}

Replication was quantified by qPCR (quantitative polymerase chain reaction) of $C$. burnetii $\mathrm{GE}$ using a primer and probe set specific to $C$. burnetii $\operatorname{dotA}$ [2]. ACCM-2 cultures were inoculated with $1 \times 10^{6}$ GE. THP-1 monocytes were differentiated into macrophage-like cells with phorbol-12-myristate-13-acetate (PMA), then infected at a multiplicity of infection (MOI) of 0.2 [40]. Samples were taken immediately and 6 days post-inoculation/infection. Each sample was diluted in $150 \mu \mathrm{l}$ phosphate-buffered saline (PBS) and boiled for $10 \mathrm{~min}$ prior to qPCR. Three independent experiments were performed in triplicate.

\section{Immunofluorescence and CCV analysis}

THP-1 cells were seeded on coverslips in 24-well plates at a density of $1 \times 10^{5}$ cells per well, stimulated with PMA for 1 day, then infected at an MOI of 10 . At 4 days postinfection, cells were fixed for $30 \mathrm{~min}$ with $4 \%$ paraformaldehyde, then permeabilized and blocked with $0.1 \%$ Triton X-100 containing $1 \%$ bovine serum albumin. Cells were fluorescently stained for CD63 (mouse monoclonal antibody H5C6, BD Pharmingen) and C. burnetii (rabbit antiNine Mile phase II strain antibody). Alexa Fluor-488 goat anti-mouse and Alexa Fluor-647 goat anti-rabbit antibodies were from Life Technologies. For staining nuclei, Hoescht 33342 (ThermoFisher) was used and for visualization of cell borders, the filamentous actin stain, BODIPY 558/568 labeled phalloidin (Life Technologies) was used. Imaging was performed on a Zeiss LSM-710 confocal fluorescence microscope (Carl Zeiss). Fiji (Image J; National Institutes of Health, USA) was used for measuring areas of CCVs, where $\mathrm{CD} 63$ served as a CCV membrane marker. A minimum of 80 cells for each infection from 3 independent experiments were used for analysis.

\section{Isolation and analysis of lipid species}

E. coli was grown to an optical density of 1 , harvested at $4000 \times g$ for $20 \mathrm{~min}$, then the pellet washed once with PBS $\left(1.5 \mathrm{mM} \mathrm{KH} \mathrm{PO}_{4}, 2.7 \mathrm{mM} \mathrm{Na} 2 \mathrm{HPO}_{4}-7 \mathrm{H}_{2} \mathrm{O}, 155 \mathrm{mM}\right.$ $\mathrm{NaCl}$, [pH 7.2]). C. burnetii was grown for 4, 7, and 14 days, harvested at 20,000 $\times g$ for $20 \mathrm{~min}$, then the pellet washed once with PBS. Lipids were extracted by the method of Bligh and Dyer [41]. Dry weights were determined and the lipids spotted onto a Silica Gel 60 TLC plate (E. coli, 150 to $200 \mu \mathrm{g}$ per lane; C. burnetii, 400 to $550 \mu \mathrm{g}$ per lane). Lipids were separated using a solvent system containing chloroform, methanol, and glacial acetic acid $(65: 25: 10, v / v)$. To visualize the lipids, TLC plates were sprayed with $10 \%$ sulfuric acid in ethanol and heated on a hot plate at $200{ }^{\circ} \mathrm{C}$. Standards were obtained from the following suppliers and used in the indicated quantities: 18:1 Lyso-PE, $50 \mu \mathrm{g}$ (Avanti Polar Lipids, Alabaster, AL); palmitoleic acid, $5 \mu \mathrm{g}$ (Sigma-Aldrich, St. Louis, MO).

\section{Statistical analysis}

Statistical analyses were performed using the unpaired Student $t$ test and GraphPad Prism 6.0 software (La Jolla, CA). 


\section{Additional files}

Additional file 1: Figure S1. Schematic of allelic exchange procedure for generation of a pldA null mutant. (TIF $87 \mathrm{~kb}$ )

Additional file 2: Table S1. Bacterial strains and plasmids used in this study. (DOCX $17 \mathrm{~kb}$ )

Additional file 3: Table S2. Oligonucleotide primers used in this study. (DOCX $14 \mathrm{~kb}$ )

\section{Abbreviations}

18-1 Lyso-PE: 18-1 lyso-phosphatidylethanolamine; ACCM-2: acidified citrate cysteine medium-2; C. burnetii: Coxiella burnetii; CCV: Coxiella-containing vacuole: CL: cardiolipin; E. coli: Escherichia coli; FFA: free fatty acid; GE: genomic equivalent; LB: Luria-Bertani; LCV: large cell variant; lyso-PL: Iyso-phospholipid; MOI: multiplicity of infection; PBS: phosphate-buffered saline; PC: phosphatidylcholine; PCR: polymerase chain reaction; PE: phosphatidylethanolamine;

PG: phosphatidylglycerol; Pl: phosphatidylinositol; PldA: outer membrane phospholipase A; PMA: phorbol-12-myristate-13-acetate; PS: phosphatidylserine; qPCR: quantitative polymerase chain reaction; Rf retardation factor; SCV: small cell variant; TLC: thin layer chromatography

\section{Acknowledgements}

We thank Anita Mora for preparation of figures.

\section{Funding}

This work was supported by the Intramural Research Program of the National Institutes of Health, National Institute of Allergy and Infectious Diseases. The funding body had no role in the design of the study and collection, analysis, and interpretation of data and in writing the manuscript.

\section{Availability of data and materials}

The datasets used and/or analysed during the current study are available from the corresponding author on reasonable request.

\section{Authors' contributions}

CMS and RAH conceived and supervised the project, and interpreted the data. PAB made pldA constructs for allelic exchange. CMS generated the pldA mutant and performed lipid extractions, TLC, and western blotting. CMS and DCC performed macrophage growth assays. CMS and RAH wrote the manuscript. HEM performed confocal microscopy and vacuole measurements All authors reviewed and approved the manuscript

\section{Ethics approval and consent to participate}

Not applicable.

\section{Competing interests}

The authors declare that they have no competing interests.

\section{Publisher's Note}

Springer Nature remains neutral with regard to jurisdictional claims in published maps and institutional affiliations.

\section{Author details}

${ }^{1}$ Coxiella Pathogenesis Section, Laboratory of Bacteriology, Rocky Mountain Laboratories, National Institute of Allergy and Infectious Diseases, National Institutes of Health, Hamilton, Montana, USA. ${ }^{2}$ Department of Chemistry, New Mexico Highlands University, Las Vegas, New Mexico, USA.

\section{Received: 29 December 2017 Accepted: 9 April 2018}

\section{Published online: 16 April 2018}

\section{References}

1. Maurin M, Raoult D. Q fever. Clin Microbiol Rev. 1999;12(4):518-53.

2. Howe D, Shannon JG, Winfree S, Dorward DW, Heinzen RA. Coxiella burnetii phase I and II variants replicate with similar kinetics in degradative phagolysosome-like compartments of human macrophages. Infect Immun. 2010;78(8):3465-74.

3. Coleman SA, Fischer ER, Howe D, Mead DJ, Heinzen RA. Temporal analysis of Coxiella burnetii morphological differentiation. J Bacteriol. 2004;186(21):7344-52.
4. Heinzen RA, Hackstadt T, Samuel JE. Developmental biology of Coxiella burnetii. Trends Microbiol. 1999:7(4):149-54.

5. McCaul TF, Hackstadt T, Williams JC. Ultrastructural and biological aspects of Coxiella burnetii under physical disruptions. In: Burgdorfer W, Anacker RL, editors. Rickettsiae and rickettsial diseases. New York, NY: academic press, Inc; 1981. p. 267-80.

6. Sandoz KM, Sturdevant DE, Hansen B, Heinzen RA. Developmental transitions of Coxiella burnetii grown in axenic media. J Microbiol Methods. 2014;96:104-10.

7. Zhang YM, Rock CO. Membrane lipid homeostasis in bacteria. Nat Rev Microbiol. 2008;6(3):222-33.

8. Chang YY, Cronan JE Jr. Membrane cyclopropane fatty acid content is a major factor in acid resistance of Escherichia coli. Mol Microbiol. 1999;33(2):249-59.

9. Domingues P, Palkovic P, Toman R. Analysis of phospholipids from Coxiella burnetii by fast atom bombardment mass spectrometry. A rapid method for differentiation of virulent phase I and low virulent phase II cells. Acta Virol. 2002;46(2):121-4.

10. Frimmelova M, Toman R, Pompach P, Skultety L. Modifications in the glycerophospholipid composition between the Coxiella burnetii phase I and phase II cells suggest an association with phase variation of the bacterium. Acta Virol. 2016;60(1):27-33.

11. Beare PA, Unsworth N, Andoh M, Voth DE, Omsland A, Gilk SD, Williams KP, Sobral BW, Kupko JJ 3rd, Porcella SF, et al. Comparative genomics reveal extensive transposon-mediated genomic plasticity and diversity among potential effector proteins within the genus Coxiella. Infect Immun. 2009;77(2):642-56.

12. Sohlenkamp C, Geiger O. Bacterial membrane lipids: diversity in structures and pathways. FEMS Microbiol Rev. 2016;40:133-59.

13. Amano K, Williams JC, McCaul TF, Peacock MG. Biochemical and immunological properties of Coxiella burnetii cell wall and peptidoglycanprotein complex fractions. J Bacteriol. 1984;160(3):982-9888.

14. Tzianabos T, Moss CW, McDade JE. Fatty acid composition of rickettsiae. J Clin Microbiol. 1981;13(3):603-5.

15. Istivan TS, Coloe PJ, Phospholipase A. In gram-negative bacteria and its role in pathogenesis. Microbiology. 2006;152(Pt 5):1263-74.

16. Beare PA, Gilk SD, Larson CL, Hill J, Stead CM, Omsland A, Cockrell DC, Howe D, Voth DE, Heinzen RA. Dot/lcm type IVB secretion system requirements for Coxiella burnetii growth in human macrophages. MBio. 2011;2(4):e00175-11.

17. Parsons JB, Rock CO. Bacterial lipids: metabolism and membrane homeostasis. Prog Lipid Res. 2013:52(3):249-1276.

18. Dowhan W. A retrospective: use of Escherichia coli as a vehicle to study phospholipid synthesis and function. Biochim Biophys Acta. 2013;1831(3):471-94.

19. Giles DK, Hankins JV, Guan Z, Trent MS. Remodelling of the Vibrio cholerae membrane by incorporation of exogenous fatty acids from host and aquatic environments. Mol Microbiol. 2011;79:716-28.

20. Bishop RE. Structural biology of membrane-intrinsic beta-barrel enzymes: sentinels of the bacterial outer membrane. Biochim Biophys Acta. 2008; 1778(9):1881-96

21. Snijder HJ, Dijkstra BW. Bacterial phospholipase a: structure and function of an integral membrane phospholipase. Biochim Biophys Acta. 2000;1488(1-2):91-101.

22. Heinzen RA, Hackstadt T. A developmental stage-specific histone $\mathrm{H1}$ homolog of Coxiella burnetii. J Bacteriol. 1996;178(16):5049-52.

23. Coleman SA, Fischer ER, Cockrell DC, Voth DE, Howe D, Mead DJ, Samuel JE, Heinzen RA. Proteome and antigen profiling of Coxiella burnetii developmental forms. Infect Immun. 2007:75(1):290-8.

24. Heinzen RA, Howe D, Mallavia LP, Rockey DD, Hackstadt T. Developmentally regulated synthesis of an unusually small, basic peptide by Coxiella burnetii. Mol Microbiol. 1996;22(1):9-19.

25. Warrier I, Hicks LD, Battisti JM, Raghavan R, Minnick MF. Identification of novel small RNAs and characterization of the 6S RNA of Coxiella burnetii. PLoS One. 2014;9(6):e100147.

26. Sandoz KM, Popham DL, Beare PA, Sturdevant DE, Hansen B, Nair V, Heinzen RA. Transcriptional profiling of Coxiella burnetii reveals extensive cell wall remodeling in the small cell variant developmental form. PLoS One. 2016:11:e0149957.

27. Thormar $\mathrm{H}$, Hilmarsson $\mathrm{H}$. The role of microbicidal lipids in host defense against pathogens and their potential as therapeutic agents. Chem Phys Lipids. 2007;150(1):1-11.

28. Katayama T, Kanno M, Morita N, Hori T, Narihiro T, Mitani Y, Kamagata Y. An oleaginous bacterium that intrinsically accumulates long-chain free fatty acids in its cytoplasm. Appl Environ Microbiol. 2014;80(3):1126-31.

29. Waltermann $M$, Steinbuchel A. Neutral lipid bodies in prokaryotes: recent insights into structure, formation, and relationship to eukaryotic lipid depots. J Bacteriol. 2005;187(11):3607-19. 
30. Voth DE, Heinzen RA. Lounging in a lysosome: the intracellular lifestyle of Coxiella burnetii. Cell Microbiol. 2007;9(4):829-40.

31. Lundbaek JA, Andersen OS. Lysophospholipids modulate channel function by altering the mechanical properties of lipid bilayers. J Gen Physiol. 1994; 104(4):645-73.

32. Bukholm G, Tannaes T, Nedenskov P, Esbensen Y, Grav HJ, Hovig T, Ariansen S, Guldvog I. Colony variation of Helicobacter pylori: pathogenic potential is correlated to cell wall lipid composition. Scand J Gastroenterol. 1997;32(5):445-54.

33. Tannaes T, Bukholm IK, Bukholm G. High relative content of lysophospholipids of Helicobacter pylori mediates increased risk for ulcer disease. FEMS Immunol Med Microbiol. 2005:44(1):17-23.

34. Pugsley AP, Schwartz M. Colicin E2 release: lysis, leakage or secretion? Possible role of a phospholipase. EMBO J. 1984;3(10):2393-7.

35. Cavard D, Baty D, Howard SP, Verheij HM, Lazdunski C. Lipoprotein nature of the colicin a lysis protein: effect of amino acid substitutions at the site of modification and processing. J Bacteriol. 1987;169(5):2187-94.

36. Wang X, Jiang F, Zheng J, Chen L, Dong J, Sun L, Zhu Y, Liu B, Yang J, Yang $G$, et al. The outer membrane phospholipase a is essential for membrane integrity and type III secretion in Shigella flexneri. Open Biol. 2016;6(9): 160073

37. Stead CM, Omsland A, Beare PA, Sandoz KM, Heinzen RA. Sec-mediated secretion by Coxiella burnetii. BMC Microbiol. 2013;13:222.

38. Omsland A, Beare PA, Hill J, Cockrell DC, Howe D, Hansen B, Samuel JE, Heinzen RA. Isolation from animal tissue and genetic transformation of Coxiella burnetii are facilitated by an improved axenic growth medium. Appl Environ Microbiol. 2011;77(11):3720-5.

39. Beare PA, Larson CL, Gilk SD, Heinzen RA. Two systems for targeted gene deletion in Coxiella burnetii. Appl Environ Microbiol. 2012;78(13):4580-9.

40. Larson CL, Beare PA, Voth DE, Howe D, Cockrell DC, Bastidas RJ, Valdivia RH, Heinzen RA. Coxiella burnetii effector proteins that localize to the parasitophorous vacuole membrane promote intracellular replication. Infect Immun. 2015;83(2):661-70.

41. Bligh EG, Dyer WJ. A rapid method of total lipid extraction and purification. Can J Biochem Physiol. 1959;37(8):911-7.

\section{Ready to submit your research? Choose BMC and benefit from:}

- fast, convenient online submission

- thorough peer review by experienced researchers in your field

- rapid publication on acceptance

- support for research data, including large and complex data types

- gold Open Access which fosters wider collaboration and increased citations - maximum visibility for your research: over $100 \mathrm{M}$ website views per year 